\title{
Multicriteria analysis of renewable-based electrification projects in developing countries
}

\author{
B. Domenech ${ }^{1 *}$, L. Ferrer-Martí ${ }^{2}$, R. Pastor $^{2}$ \\ ${ }^{1}$ Serra Húnter Fellow, Department of Management (DOE), Institute of Industrial and Control Engineering \\ (IOC), Universitat Politècnica de Catalunya (UPC) - Barcelona Tech \\ ${ }^{2}$ Department of Mechanical Engineering (DEM), IOC - UPC \\ ${ }^{3}$ Department of Management (DOE), IOC - UPC \\ Corresponding author (*): bruno.domenech@upc.edu; (+34) 934.017.076
}

\begin{abstract}
The design of wind-photovoltaic stand-alone electrification projects that combine individual systems and microgrids is complex and requires from support tools. In this paper, a multicriteria procedure is presented in detail, which aims to assist project developers in such a design. More specifically, the procedure has been developed under a four-part structure, using support tools and expert consultations to enhance practicality into the rural context of developing countries. First, from a large amount of criteria, a reduced and easy to handle set is chosen, representing the main characteristics to be assessed in rural electrification projects. Second, two iterative processes, one based on the Analytical Hierarchy Process and one based on a typical 1-10 assessment, are tested to assign weights to the criteria, reflecting end-user preferences. Third, some indicators are proposed to evaluate the accomplishment of each solution regarding each criterion, in an objective manner. Fourth, considering the weights and evaluations, the solutions are ranked, using the compromise programming technique, thus selecting the best one/s. The whole procedure is illustrated by designing the electrification project of a real community in the Andean highlands. In short, this paper provides insights about the suitable decision-making process for the design of wind-PV electrification systems and, in addition, shows how different multicriteria techniques are applied to a very local context in rural, remote and very poor areas of developing countries.
\end{abstract}

Keywords: rural electrification; microgrids; multicriteria; compromise programming.

\section{Introduction}

"Ensure access to affordable, reliable, sustainable and modern energy for all" has been defined by the United Nations as the seventh Sustainable Development Goal (UN 2015). In fact, the link between the Human Development Index (HDI) and electricity consumption has been widely demonstrated. For less developed regions, small increases in electricity consumption lead to large increases in HDI, thus improving the quality of life. However, there are still 1.1 billion people without such service, especially in rural areas of developing countries (IEA 2017). In this sense, each person should have, at least, around $50-100 \mathrm{kWh}$ of electricity per year in 2030 .

The conventional strategy to expand electricity access is the national grid, but significant techno-economic constraints can appear in mountainous or remote areas, due to the complex terrain, the dispersion between communities and houses, and the low consumption levels (Ferrer-Martí et al. 2012). Alternatively, stand-alone electrification systems based on renewable energy are suitable to provide electricity to isolated communities, reducing greenhouse gas emissions (Ubilla et al. 2014). In particular, the wind and solar photovoltaic (PV) technologies are increasingly used since they are virtually worldwide (Dinçer 2011; Leary et al. 2012). Hybrid wind-PV systems are particularly interesting, as they generally complement to each other and reduce project 
costs while increasing supply quality (Notton et al. 2011). Regarding the electricity distribution from generators to end-users, many projects use individual systems due to their technical simplicity and the dispersion between houses (Chaurey and Kandpal 2010). Microgrids are receiving increased attention, given their advantages such as a greater equity and flexibility in consumption or cost savings through economies of scale (Ustun et al. 2011; Ferrer-Martí et al. 2012).

In medium-dispersed communities, where neither individual systems nor microgrids are evident, the combination of different generation and distribution technologies is not straightforward (Domenech et al. 2014). On the one hand, all possible wind-PV generator combinations should be examined in order to satisfy the demand, according to the energy resources. On the other hand, all possible connections between points should be analysed, balancing microgrids extension (and subsequent benefits) and cost increases (when connecting far points). However, project promoters in rural areas of developing countries, mainly NGOs and local governments, usually have limited techno-economic resources (Escobar et al. 2012). Consequently, standardized solutions are commonly replicated, rather than studying the specific characteristics of each community (Schäfer et al. 2011). In this context, decision-making support tools can assist promoters to design suitable electrification systems (Hiremath et al. 2007).

The literature regarding the design of stand-alone electrification systems is wide, developing mathematical models and heuristic algorithms (Zhou et al. 2010; Baños et al. 2011; Bhattacharyya 2012; Kuznia et al. 2013; Gamarra and Guerrero 2015). In fact, linear programming is an adequate tool to reach optimal or near-optimal solutions for optimisation problems (Atamtürk and Savelsbergh 2005). Many works focus on sizing a combination of generation technologies to cover the demand at a minimum cost, according to the energy resources. The most common tool is HOMER (Lal et al. 2011), which considers a high detail in the analysis of the demand, the energy resources and the equipment to be implemented. In contrast, the electricity distribution from generators to end-users has been less studied for medium-dispersed areas, balancing microgrids extension and cost increases (Rojas-Zerpa 2012). Among the few existing tools, ViPOR (Lambert and Hittle 2000) considers the terrain orography as well as the location and electricity needs of each point to evaluate, through the simulated annealing heuristic, its electrification through a single microgrid or an individual system. Nevertheless, the above tools do not consider the multicriteria nature of energy systems (Pohekar and Ramachandran 2004; Karger and Hennings 2009). In addition, social aspects are not examined, despite being a key issue for the sustainability of electrification projects, especially in developing countries (Lillo et al. 2015).

Alternatively, several works focus on a multicriteria assessment of scenarios or electrification options, using decision support techniques (Pohekar and Ramachandran 2004; Alarcón-Rodríguez et al. 2010; Rojas-Zerpa and Yusta 2015). In this way, several criteria can be simultaneously evaluated, managing quantitative and qualitative preferences of end-users for some aspects in the options to be assessed. On the other hand, not a single solution is obtained from the input data, as it happens with optimisation models, but several design options are examined at the same time. Therefore, the solution finally selected is less dependent on the quality of the information gathered; which may be useful in areas where data access is not easy (Alfaro et al. 2017). An example of multicriteria tool is SURE (Henao et al. 2012), which uses compromise programming to assess the impact that several technologies may have on the target community, selecting 
the most suitable one according to physical, financial, natural, social and human criteria. However, most multicriteria tools evaluate predefined scenarios, without analysing the detail of the electrification system neither defining the way as they are obtained (RojasZerpa and Yusta 2015). Therefore, they can be used as a global assessment rather than a tool for the analysis of local-scale solutions.

From an extensive literature review, Bhattacharyya (2012) suggests hybrid approaches to design energy systems, combining optimisation and multicriteria techniques, among others. In areas where data gathering is not easy, Mavrotas et al. (2003) and AlarcónRodríguez et al. (2010) recommend, first, developing efficient solutions through optimisation models and, second, selecting the best one through multicriteria processes. Thus, a higher realism in representing the problem is achieved and decisions are taken knowing part of the problem beforehand. In this context, Domenech et al. (2015a) propose a methodology to assist rural electrification promoters in projects design, considering a great detail of solutions as well as economic, technical and social issues. The decisionmaking is organised in three levels, studying the influence on the cost of modifications on the energy uses covered (level 1), the management of the system (level 2) and the adequacy of equipment (level 3). At each level, a set of efficient solutions is generated, using a mathematical model, and then the most suitable one is selected. In this work, the multicriteria procedure developed for the selection process is presented, organised in four parts (Wang et al. 2009): definition of criteria, weighting of criteria, evaluation of alternatives and aggregation of results. Hence, the contribution of this paper is twofold:

1. To present in detail the four parts of the multicriteria procedure. First, a reduced and easy to handle set of evaluation criteria is defined from a larger amount initially proposed through expert consultations. Such criteria represent the main characteristics to be assessed in rural electrification projects. Second, two iterative processes are tested to assign weights to the criteria, representing the preferences of end-users for each criterion regarding the others. One uses the Analytical Hierarchy Process (AHP), based on pair-wise comparisons, and the other one uses a typical 1-10 assessment. Third, some indicators are proposed to evaluate the accomplishment of each electrification solution regarding each criterion, in an objective manner. Finally, fourth, considering the weights and evaluations, the compromise programming technique is utilised to rank the solutions according to their suitability for the target community. This technique calculates the closeness of each solution with regards to a utopian solution where all the criteria attain their optimum value (ideal solution).

2. To show how different multicriteria techniques are adapted to a very local context in rural areas of developing countries, where the means and techno-economic resources for electrification projects implementation are very limited. This fact can be observed both in the development of the multicriteria procedure and in its illustration to design the electrification project of a real community in the Andean highlands.

The remainder of the paper is organised as follows. Section 2 presents a review of the state-of-the-art on multicriteria tools used for the design of electrification systems. In Section 3, a context for the development of the multicriteria procedure is provided. Sections 4 and 5 explain the multicriteria procedure, organised in a four-part framework. In Section 6, the multicriteria procedure is illustrated through its application to a case study. Finally, the main conclusions are summarized in Section 7. 


\section{Literature review on multicriteria methods for electrification projects design}

Multicriteria decision-making methods allow several alternatives to be compared without requiring arbitrary monetization of evaluation criteria, making them suitable for complex decision problems, such as the design of stand-alone electrification systems (AlarcónRodriguez et al. 2010; Rojas-Zerpa and Yusta 2015). As mentioned before, according to Wang et al. (2009) the multicriteria procedure to select the most adequate solution from a set of solutions is organised in four parts: definition of criteria, weighting of criteria, evaluation of alternatives and aggregation of results. Next, the literature review is structured according to these parts.

The definition of criteria consists in determining a set of criteria to assess the alternatives. Criteria are generally divided into four categories (Wang et al. 2009): economic, technical, social and environmental; most publications adapt this definition to the particularities of their problem (Afgan et al. 2000). Differences in divisions are mainly due to a change in the context or the scale. Large-scale social criteria tend to have economic implications, such as job creation (Karger and Hennings 2009). Nevertheless, in developing regions some of these criteria must be reconsidered (Ostergaard 2009), since the priority is to provide access to electricity at an affordable cost. On the other hand, the management of the system and the security of supply must be included to ensure the project's sustainability (Chatzimouratidis and Pilavachi 2009; Lillo et al. 2015). However, when selecting criteria, the following recommendations should be considered (Afgan et al. 2000; Bertsch and Fichtner 2016): (a) to choose enough criteria to represent the points of view of all stakeholders; (b) to avoid too many criteria, which could hamper consensus; and (c) to select measurable criteria to permit a clear and concise analysis.

The weighting of criteria consists in assigning a value to each criterion representing its relevance with regard to the others. When working with several criteria, weighting them may not be evident, but some techniques can aid the analysis (Wang et al. 2009). Direct assignment methods are easy-to-use but they have a strong subjective load. In contrast, peer comparison methods can reduce subjectivity, although they are more complex. Among others, the Analytic Hierarchy Process (AHP) allows a consistency index to be calculated, which indicates weighting's consistency (Saaty 2003; Chatzimouratidis and Pilavachi 2009). Many other methods with mathematical foundations exist, but do not directly reflect the points of view of decision-makers, so they have been used less - or not at all - for rural energy planning (Wang et al. 2009).

The evaluation of alternatives consists in assessing each alternative regarding each criterion. This is generally the most complex part of the whole multicriteria comparison and selection process. There are many tools to aid decision-making applied to energy planning problems (Zhou et al. 2006; Alarcon-Rodriguez et al. 2010; Rojas-Zerpa and Yusta 2015). There are even studies focusing on the proper selection of a multi-criteria technique, which is itself a multi-criteria decision (Polatidis et al. 2006). Next, some of the most relevant are presented, following the classification proposed by Loken (2007):

- Value measurement models. A value is assigned to each alternative and then alternatives are classified following a dominancy logic. Among others, the MultiAttribute Value Theory (MAVT), the Multi-Attribute Utility Theory (MAUT) and the AHP must be highlighted (Rojas-Zerpa and Yusta 2014; Schäfer 2015). These methods are simple, transparent and interactive, and their use is widespread. 
However, they require many resources to obtain results and allow no hesitation when comparing alternatives with each other (Pohekar and Ramachandran 2004; Polatidis et al. 2006). Therefore, they are progressively less used in rural projects in developing countries where access to information is not always easy (Zhou et al. 2006).

- Improvement models. A value is assigned to each alternative by peer-comparing them with regard to each criterion; then the alternatives are classified following a dominancy logic, assuming some uncertainty thresholds. Among others, ELECTRE and PROMETHEE must be highlighted (Rojas-Zerpa and Yusta 2014; Mardani et al. 2015; Schäfer 2015). These models are increasingly used in rural energy planning since they allow the possibility of compensations between criteria (Polatidis et al. 2006; Zhou et al. 2006) to be avoided. However, the concept of thresholds is not always clear and the methods tend to be seen as black boxes with unknown internal processes (Loken 2007), so they are not always suitable in developing regions.

- Goal, aspiration and reference models. A value is assigned to each alternative and then alternatives are compared with an ideal solution. Among others, goal programming and compromise programming must be highlighted (Rojas-Zerpa and Yusta 2014; Colapinto et al. 2017). These methods are generally easy-to-use, less subjective than value measurement models and allow the decision-maker to interact (Loken 2007). When the number of criteria is limited, compromise programming has proven beneficial. For instance, Garcia-Bernabeu et al. (2016) use such method for risk assessment of PV installations with financial government support. Similar tools to compromise programming have been also utilised. The Technique for Order Performance by Similarity to Ideal Solution (TOPSIS) complements the ideal solution concept with the anti-ideal, which is the worst solution for all criteria, and has been used for PV applications (García-Cascales et al. 2012). VIKOR is a comprehensive tool that schematises decision-making and has been use for the location of electricity generation systems in disaster relief camps (Malekpoor et al. 2018).

Finally, the aggregation of results arises from the fact that there is no single method which is suitable for a specific problem and vice versa. In fact, the same method applied by different decision-makers or different methods applied by the same decision-maker can lead to different results (Polatidis et al. 2006; Loken 2007). Thus, more than one method can be used and, if results are different, some mathematical methods allow converging differences (Wang et al. 2009). However, this is generally studied theoretically rather than in real cases, especially in rural electrification projects in developing countries where resources are limited.

Multicriteria techniques have proved suitable to assess rural development projects in developing countries (Sanchez-Lopez et al. 2012). In fact, their use for the design of rural electrification projects in developing countries is a dynamic research area. Most reviewed works mainly focus on the decision-making process itself, but not the specific characteristics of the target communities to be evaluated. Moreover, the scope of application is generally addressed to regional-scale problems, evaluating global indicators and large solutions. In contrast, the application of multicriteria tools to a local context has been less studied, probably because of the limited techno-economic resources available in rural regions of developing countries. In this context, the proposed multicriteria procedure aims to bridge the existing gap, by addressing very local characteristics when addressing the design of electrification projects in rural areas of developing countries. 
In terms of support techniques, the AHP has proved suitable for weighting criteria, while the compromise programing has shown benefits for the criterion-solution assessments. Both techniques facilitate interaction along the decision-making process, which may improve the confidence of end-users on the results obtained, while progressively adapting the design to the population characteristics. All these characteristics have been considered for the development of the proposed multicriteria procedure, in order to address particular issues of rural areas in developing countries not examined in the literature. Finally, note that the four-part structure proposed by Wang et al. (2009) for decision-making is adapted by several authors to the specific issues of each problem solved. In this work, the definition and weighting of criteria are firstly explained (Section 4) and then the evaluation of alternatives and the aggregation of results are described (Section 5). Thus, the two key moments where end-users have to directly take decisions (to assign the weights of criteria and to analyse the ranking of alternatives) can be clearly distinguished.

\section{Multicriteria procedure}

In this section, the problem dealt with in this study is described. First, the technical scheme of stand-alone rural electrification projects is presented, as well as social issues that can be a handicap for projects sustainability (Section 3.1). Then, a context for the development of the multicriteria procedure is provided, based on the work from Domenech et al. (2015a) (Section 3.3).

\subsection{Problem design}

In stand-alone electrification projects based on wind-PV energy, the electricity is produced by wind turbines and PV panels. Next, controllers are installed between generators and batteries, to protect such devices from overloads and deep discharges. Batteries allow storing the electricity generated in periods with energy resources (wind and/or sun), then supplying it to consumption points (houses, schools, health centres, community centres, churches, etc.) in periods without resources. Afterwards, inverters transform the direct current, used in battery storage, into alternating current, which is more suitable for most electrical appliances. To distribute the electricity to consumption points, individual systems or microgrids can be used. Microgrids have a radial scheme, i.e. the form of a tree (Phrakonkham et al. 2010). Additionally, meters are installed at consumption points to control the electricity used.

As explained in the introduction, including social aspects in the design of electrification projects for rural communities in developing countries is a key issue for ensuring projects sustainability and the socioeconomic development of population. In particular, inappropriate technical designs may cause social problems. Domenech et al. (2015b) analyse different electrification projects in the Andean highlands, identifying their main limitations and proposing technical solutions to improve the social impact:

- Covered energy uses. In some projects the electric supply is below the population's expectations, so end-users do not see their needs met. In other cases, some projects are oversized, causing disproportionate investment and maintenance costs for real electricity usage. In both cases the population's development is at risk. To avoid this problem a detailed analysis of electricity demand is required. 
- Management of the system. Microgrids have many advantages compared with individual systems. However, these configurations entail the coordination of connected end-users, who can sometimes have conflicting interests. Therefore, microgrids must be extended as much as possible, although cautiously, to avoid projects combining too many small microgrids within the same community. In parallel, the tariff that end-users have to pay for electricity consumption must be studied in detail. In this regard, meters are devices that raise the project cost but allow the consumption at each point to be measured.

- Adequacy of equipment. This issue is related to the security of supply when faced with the lack of energy resources or equipment breakdowns. Favouring the solar resource (generally less variable than the wind) or using a minimum amount of equipment at generation points - to minimize the negative impacts of failure in one of them - are suitable options whose cost should be studied. Besides, the benefits of microgrids as opposed to individual users can also be compensated by a small energy supply increase, to prevent different development opportunities for end-users.

\subsection{Design methodology}

As explained previously, Domenech et al. (2015a) develop a methodology (Fig. 1) to design wind-PV electrification projects that combine microgrids and individual systems. Next, this methodology is summarised in order to provide a context for the development of the multicriteria procedure developed in this paper.

Before starting, the information needed for the design is gathered: the socioeconomic characteristics of the population, the community and its surroundings; the potential of the wind and sun resources at each point and the technical and economic characteristics of the equipment available in the region. Afterwards, the design process itself can start. As mentioned, a two-step philosophy is followed: first generating a set of efficient solutions and then selecting the most suitable one. However, due to the amount of design considerations included and in order to ease the decision-making, the process is organised at three decision levels, ordered according to the importance of the decisions taken:

- Level 1 - Strategic decisions. The influence on the cost of modifications in the electrical demand is studied. In order to study the best compromise between the cost and the demand, a set of alternatives is obtained when the cost is minimized for different levels of: energy, power and autonomy needs.

- Level 2 - Tactical decisions. The influence on the cost of modifications in the configuration of the electrical distribution is examined to ease the management of the system. Four constraints are considered:

○ Maximum number of microgrids, to avoid implementing too many microgrids within the same community.

- Minimum number of points per microgrid, to avoid devoting efforts to the management of too small microgrids.

- Maximum number of individual points, to extend as much as possible the benefits of microgrids instead of individual points.

- Installing meters at all the points (to establish a payment rate according to their consumption) or only at microgrid points (to save costs). 
- Level 3 -Operational decisions. The influence on the cost of modifications in the typology of equipment is studied to improve the security of supply. Three constraints are considered:

- Minimum percentage of the energy generated by PV panels, since the solar resource is more constant than wind.

- Minimum amount of generation equipment at generation points, ensuring that if one fails at least one other will still supply the electricity.

- Additional energy percentage to individual points in order to compensate for their disadvantages compared with microgrids.

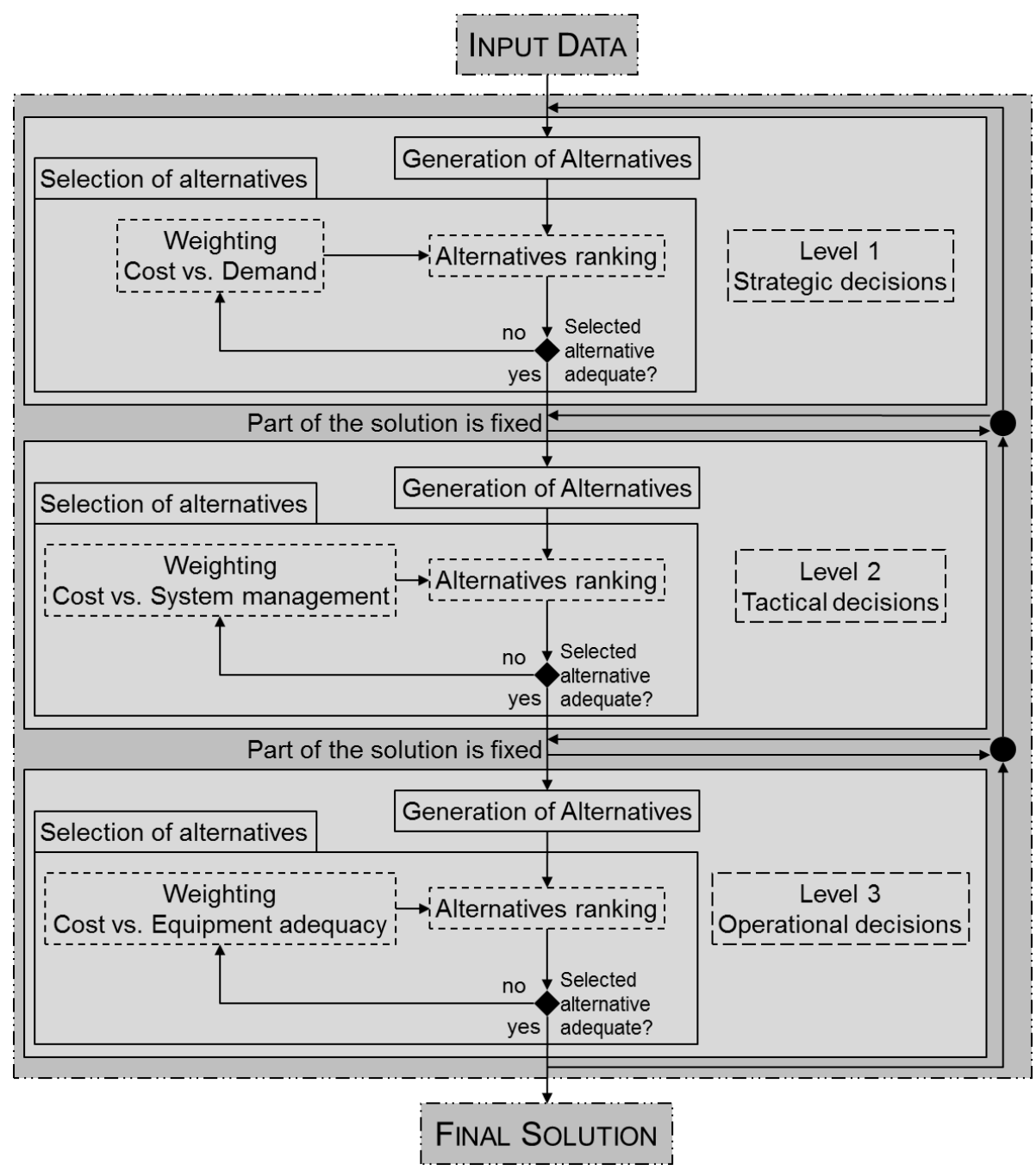

Fig. 1 - Scheme of the design methodology (adapted from Domenech et al. 2015a)

Each decision level is divided into two steps. First, in the "Generation of alternatives" step, a set of electrification alternatives is generated using a mathematical model (Domenech et al. 2015b). The model designs the technical system, minimizing the cost as well as satisfying constraints related to: technical issues (Level 1), the electric distribution configuration (Level 2) and the typology of equipment (Level 3). Then, in the "Selection of Alternatives" step, the compromise programming multicriteria technique is used to select the best of the generated alternatives based on economic, technical and social criteria. The alternative selected at one level is used as the starting point for the next one. Additionally, between two consecutive levels, part of the solution of the selected alternative is fixed to prevent decisions of lower levels modifying 
decisions taken in the previous and more important levels. Moreover, the generation and selection of alternatives are complemented by an iterative procedure that allows trying many design options by going from the end of one decision level to the beginning of any of the above. Thus, the promoter of the project does not need to try all the design options from the beginning, but new alternatives can be generated when dealing with the problem in-depth, depending on the results obtained so far.

\section{Definition and weighting of criteria}

This section is structured in three parts. In Section 4.1, the initial definition of criteria is presented and analysed. Next, in section 4.2, the proposal of the definitive criteria is explained and the weighting processes are described in Section 4.3.

\subsection{Initial definition of criteria}

The design criteria should consider the preferences of all stakeholders involved in the design process: promoters, local and regional authorities, and future beneficiaries. To define them, first of all the literature mentioned in Section 2 was reviewed, as well as tools related to the design of rural electrification projects. Moreover, some experts on rural electrification from the NGOs Practical Action - Intermediate Technology Development Group (PA) from Peru, Engineering Without Borders (EWB) from Spain and Green Empowerment $(G E)$ from the USA were consulted and participated in the definition process. These experts had experience in many contexts, especially in the coastal, mountainous and jungle regions of Bolivia, Ecuador and Peru. Through them, an initial definition of a set of criteria to evaluate electrification projects in rural areas of developing countries was obtained.

As a result of the literature review and expert surveys, 28 evaluation criteria were obtained. However, Nijkamp et al. (1990) state that a rational decision-maker is not able to consider more than 7-12 criteria simultaneously. Consequently, the criteria were grouped. Thus, decision-makers can focus on specific topics and sub-topics, easing the weighting of criteria (and subcriteria) and the evaluation of alternatives. In particular, the 28 initial criteria were grouped into 14 criteria (each one having 1-3 subcriteria) which, in turn, are divided in two broad categories: social and technical (Table 1).

Once the evaluation criteria were defined, tests were conducted to determine whether the weighting of criteria was simple, using an illustrative real case study. These tests were carried out with 7 sociologists and 7 expert technicians from the PA and EWB. The community of Alto Peru (Domenech et al. 2014) was used, as all experts knew their characteristics. The weighting of criteria was based on the Delphi method (Scott 2001): experts give anonymous opinions and then results are discussed together; this is repeated iteratively until reaching agreement. The most relevant iterations are outlined below.

Iteration 1. First, experts were requested to assign weights to each criterion from 1 to 10 , depending on their significance regarding the others. However, many experts had difficulties understanding whether a one-unit increase (or decrease) in a criterion weight was very significant or not. Moreover, some of them tended to assign greater values to all the weights than other experts. As a result of these inconveniences, the experts concluded that the weights assigned did not always reflect their real preferences. 
Table 1 - Initial definition of social and technical criteria and subcriteria

\begin{tabular}{|c|c|c|c|c|}
\hline & & Criteria & & Subcriteria \\
\hline \multirow{12}{*}{$\begin{array}{c}\text { Social } \\
\text { category }\end{array}$} & \multirow{3}{*}{$\mathbf{S}_{1}$} & \multirow{3}{*}{ Management } & $\mathbf{S}_{1-1}$ & Management of electrical systems at domestic level \\
\hline & & & $\mathbf{S}_{1-2}$ & Management of electrical systems at community level \\
\hline & & & $\mathbf{S}_{1-3}$ & Possibility of conflicts appearing between users \\
\hline & \multirow{2}{*}{$\mathbf{S}_{\mathbf{2}}$} & \multirow{2}{*}{ Equity } & $\mathbf{S}_{2-1}$ & Equity in supply between users \\
\hline & & & $\mathbf{S}_{2-2}$ & Beneficiaries of electric service within the community \\
\hline & $\mathbf{S}_{\mathbf{3}}$ & Economic & $\overline{S_{3-1}}$ & Effort that electric service tariff represents for users \\
\hline & \multirow{2}{*}{$\mathbf{S}_{4}$} & \multirow{2}{*}{$\begin{array}{l}\text { Domestic } \\
\text { benefits }\end{array}$} & $\overline{S_{4-1}}$ & Incomes though productive activities at domestic level \\
\hline & & & $\mathbf{S}_{4-2}$ & Degree of domestic comfort with electric devices \\
\hline & \multirow{2}{*}{$\mathbf{S}_{5}$} & \multirow{2}{*}{$\begin{array}{l}\text { Community } \\
\text { services }\end{array}$} & $\mathbf{S}_{5-1}$ & Benefits of electricity at health centres \\
\hline & & & $\mathbf{S}_{5-2}$ & Benefits of electricity at schools \\
\hline & $\mathbf{S}_{6}$ & Productivity & $\overline{S_{6-1}}$ & Incomes through productive activities at domestic level \\
\hline & $\mathbf{S}_{7}$ & Impact & $\mathbf{S}_{7-1}$ & Land occupation of equipment \\
\hline \multirow{16}{*}{$\begin{array}{l}\text { Technical } \\
\text { category }\end{array}$} & \multirow{3}{*}{$\mathbf{T}_{\mathbf{1}}$} & \multirow{3}{*}{ Economic } & $\mathbf{T}_{1-1}$ & Investment cost per user \\
\hline & & & $\mathbf{T}_{1-2}$ & Global investment cost \\
\hline & & & $\mathbf{T}_{1-3}$ & Operation and maintenance costs \\
\hline & \multirow{2}{*}{$\mathbf{T}_{2}$} & \multirow{2}{*}{ Supply } & $\mathbf{T}_{2-1}$ & Supplied energy per user \\
\hline & & & $\mathbf{T}_{2-2}$ & Supplied power per user \\
\hline & \multirow{2}{*}{$\mathbf{T}_{3}$} & \multirow{2}{*}{ Continuity } & $\mathbf{T}_{3-1}$ & Continuity of energy resources during project lifetime \\
\hline & & & $\mathbf{T}_{3-2}$ & Batteries autonomy for periods without energy resources \\
\hline & \multirow{2}{*}{$\mathbf{T}_{4}$} & \multirow{2}{*}{ Flexibility } & $\mathbf{T}_{4-1}$ & Ease of including new users to the system \\
\hline & & & $\mathbf{T}_{4-2}$ & Flexibility to increase consumption sporadically \\
\hline & \multirow{2}{*}{$\mathbf{T}_{5}$} & \multirow{2}{*}{ Replacement } & $\mathbf{T}_{5-1}$ & Technical assistance to repair small breakdowns \\
\hline & & & $\mathbf{T}_{5-2}$ & Technical assistance to repair big breakdowns \\
\hline & \multirow{3}{*}{$\mathbf{T}_{6}$} & \multirow{3}{*}{ Manufacturing } & $\mathbf{T}_{6-1}$ & Closeness of general equipment providers \\
\hline & & & $\mathbf{T}_{6-2}$ & Closeness of specific equipment providers \\
\hline & & & $\mathbf{T}_{6-3}$ & Availability of technicians for equipment installation \\
\hline & \multirow{2}{*}{$\mathbf{T}_{7}$} & \multirow{2}{*}{ Security } & $\mathbf{T}_{7-1}$ & Reliability when faced with failures in equipment \\
\hline & & & $\mathbf{T}_{7.2}$ & Quantity of equipment at generation points \\
\hline
\end{tabular}

Iteration 2. To ease the weighting process, a classification of criteria according to their significance was requested, by assigning values from 1 (less important) to 7 (more important) to each of the criteria from the social and technical categories. Results are shown in Fig. 2, grouped according to the category and the type of expert (sociologists or technicians). Blue squares represent the opinion of each expert, while red dots show the average weight. The results obtained varied widely.

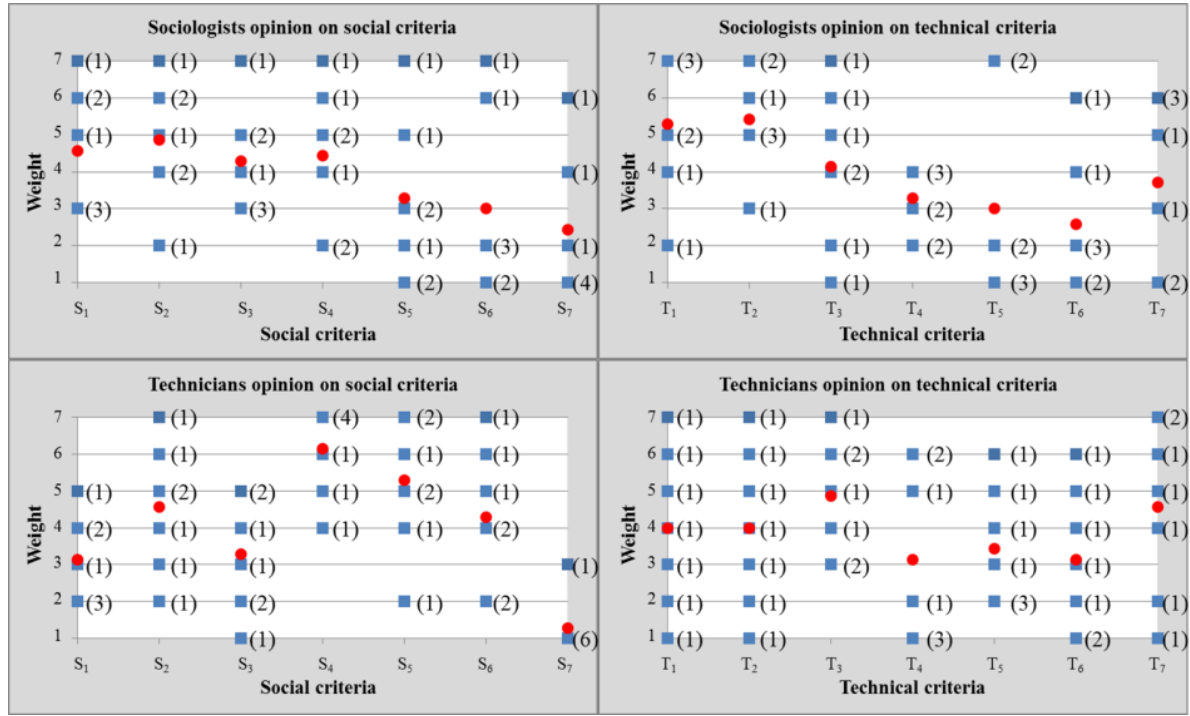

Fig. 2 - Experts weighting of social and technical criteria 
Iteration 3. To avoid the problems identified in Iteration 2, the same assignment process was repeated but only with the most experienced 3 sociologists and 3 technicians (Fig. 3). Even though a smaller variety of responses is observed, a certain scattering still remains, especially when experts decide about their specialisation (sociologists for social criteria and technicians for technical ones). Indeed, the experts decide on their specialisation criteria according to their own experience (which is different in each case), while they decide on other criteria according to what they have heard in their surroundings. Theoretically, consensus could be reached through iterative discussions and experts' consultations, but it was noted that the experts were unlikely to change their minds.

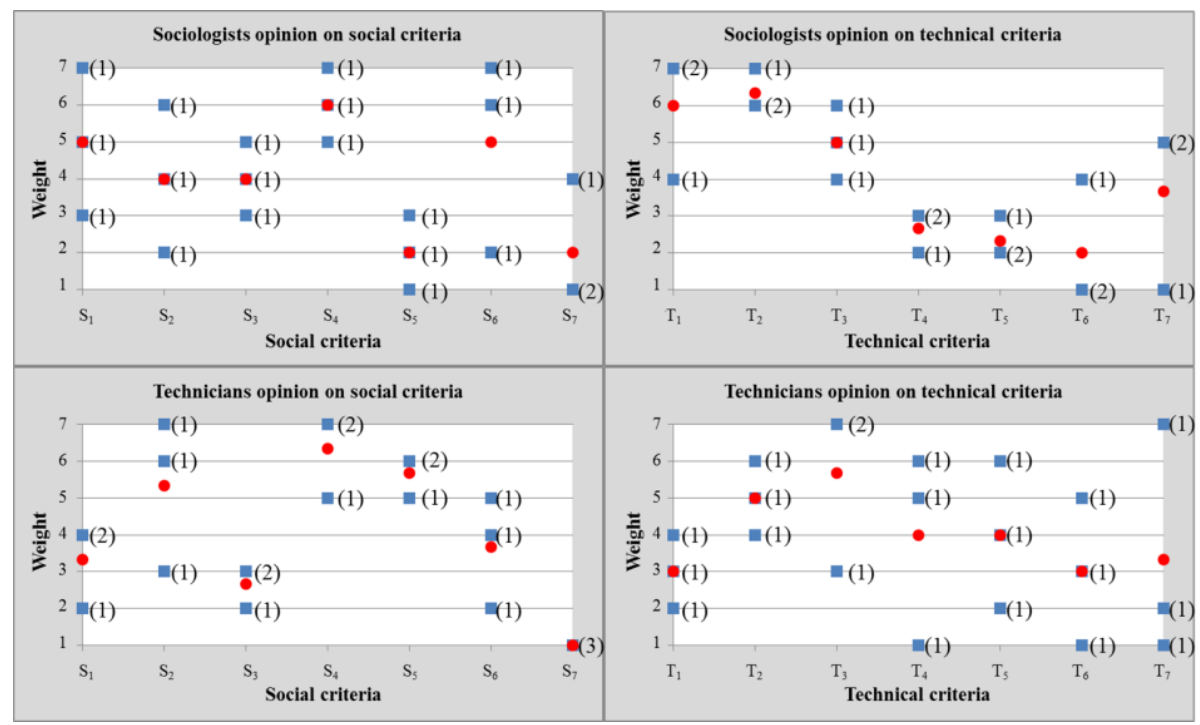

Fig. 3 - Most experienced experts weighting of social and technical criteria

Thus, it was concluded that considering all the criteria simultaneously was confusing, even for experienced rural electrification promoters, because there were too many criteria.

\subsection{Definition of definitive criteria}

Bearing in mind previous experiences, the 14 social and technical criteria (and their subcriteria) are grouped into 4 generic criteria and their corresponding subcriteria. This clustering is developed from the authors' experience acquired through collaboration with PA, EWB and GE, as well as the participation of some experts from such NGOs. The generic criteria and subcriteria are defined according to: (a) the three decision level structure of the design methodology (Domenech et al. 2015a), ordered according to the importance of the decisions taken; and (b) the way that promoters from PA, EWB and GE generally conceived rural electrification projects. Table 2 presents the definitive criteria and their weights (to be explained in section 4.3).

- The cost is the only criteria opposed to the others and is a huge limitation in such projects in developing countries; therefore, it is considered at the three decision levels.

- The demand has a great influence on solutions, since its modification entails planning the whole project again. This is the first element defined in a project, so it is considered at the first decision level.

- The management of the system has a medium influence on solutions, since its modification can be conceived within a project but with a considerable economic, technical and social effort. After defining the demand, the way that electricity is 
distributed (the electrical distribution configuration) is generally defined, so it is considered at the second decision level.

- The adequacy of equipment has a low influence on solutions, since it can be easily modified. Once the management of the system has been conceived, the typology of equipment to be used is defined, so it is considered at the third decision level.

Table 2 - Definitive criteria, subcriteria and weights for the 3 decision levels

\begin{tabular}{|c|c|c|c|c|c|c|}
\hline Level & & Criteria & Weight & & Subcriteria & Weight \\
\hline \multirow{4}{*}{ First } & $\mathrm{CF}_{1}$ & Cost & 0,48 & & - & \\
\hline & \multirow{3}{*}{$\mathbf{C F}_{2}$} & \multirow{3}{*}{ Demand } & \multirow{3}{*}{0,52} & $\mathrm{CF}_{2-1}$ & Energy & 0,40 \\
\hline & & & & $\mathrm{CF}_{2-2}$ & Power & 0,32 \\
\hline & & & & $\mathrm{CF}_{2-3}$ & Autonomy & 0,28 \\
\hline \multirow{5}{*}{ Second } & $\mathbf{C S}_{\mathbf{1}}$ & Cost & 0,48 & & - & \\
\hline & \multirow{4}{*}{$\mathbf{C S}_{2}$} & \multirow{4}{*}{$\begin{array}{l}\text { Management } \\
\text { of the system }\end{array}$} & \multirow{4}{*}{0,52} & $\mathbf{C S}_{2-1}$ & Amount of microgrids & 0,20 \\
\hline & & & & $\mathbf{C S}_{2-2}$ & Size of microgrids & 0,30 \\
\hline & & & & $\mathrm{CS}_{2-3}$ & Reach of microgrids & 0,32 \\
\hline & & & & $\mathrm{CS}_{2-4}$ & Meter installation & 0,18 \\
\hline \multirow{4}{*}{ Third } & $\mathbf{C T}_{1}$ & Cost & 0,47 & & - & \\
\hline & \multirow{3}{*}{$\mathbf{C} \mathbf{T}_{2}$} & \multirow{3}{*}{$\begin{array}{l}\text { Adequacy of } \\
\text { equipment }\end{array}$} & \multirow{3}{*}{0,53} & $\mathrm{CT}_{2-1}$ & PV generation percentage & 0,38 \\
\hline & & & & $\mathrm{CT}_{2-2}$ & No. of generation equipment & 0,30 \\
\hline & & & & $\mathbf{C T}_{2-3}$ & Energy of individual users & 0,32 \\
\hline
\end{tabular}

\subsection{Weighting of criteria}

Once the evaluation criteria and sub-criteria to be used have been defined, they must be weighted. As mentioned in Section 3.4, an iterative process is used for this purpose. Thus, the decision-maker can progressively adjust the weights until the classification of alternatives (which is explained in Section 5) completely reflects his/her preferences. However, the first iteration can still be confusing since no orientation on results is available, especially for decision-makers with limited experience. In exchange, having some predefined starting weights would allow an initial classification of alternatives to be obtained automatically; then the weights could be modified more easily, if the decision-maker deems it necessary. In other words, for instance, it is easier to determine whether top-ranked alternatives are too expensive or too cheap, rather than assigning a weight to represent the importance of the cost compared with another criterion.

For this purpose, following the work described in Sections 4.1 and 4.2, 8 experts from PA and EWB are interviewed in detail to define the starting criteria weights that could be used to obtain an initial ranking of electrification alternatives. To do so, two different types of surveys are proposed:

- AHP survey. This survey compares the criteria per pairs. Each expert compares each pair of criteria (and subcriteria) from each level, following a 1-9 scale according to their relative importance (Saaty 2003). With this information, a weighting vector is obtained for each expert, using the eigenvector method (Saaty 2003). A consistency ratio $(\mathrm{CR})$ is also obtained, indicating the coherence of the pair-wise comparison. Finally, a single weighting vector is calculated as the average of the weightings from each expert. This survey is proposed since AHP is an easy-to-use and transparent method that allows consensus to be reached, and has been used successfully in developing countries (Pohekar and Ramachandran 2004; Garfí et al. 2011). 
- Typical survey. This survey consists in assigning a weight between 0 and 10 to each criterion and subcriterion. This survey is proposed because the design methodology is supposed to be used by rural electrification promoters in developing countries, who often have limited knowledge of multicriteria techniques, and may not feel comfortable with the pair comparison.

Table 3 shows the results for AHP and the typical surveys. In both cases the average weights for the two criteria of each level, as well as for the three/four subcriteria, are listed. Furthermore, for the AHP survey the number of experts whose CR is greater than 0.1 are shown, a value commonly considered as the maximum acceptability threshold (Saaty 2003). The average of CR is also shown.

Table 3 - Results of the typical and AHP surveys for criteria and subcriteria weights

\begin{tabular}{|c|c|c|c|c|c|c|c|}
\hline & \multicolumn{4}{|c|}{ AHP survey } & \multicolumn{2}{|c|}{ Typical survey } \\
\hline & & $\begin{array}{c}\text { Experts } \\
\text { with a } \mathrm{CR}>0.1\end{array}$ & Average CR & Average & $\begin{array}{l}\text { Standard } \\
\text { deviation }\end{array}$ & Average & $\begin{array}{l}\text { Standard } \\
\text { deviation }\end{array}$ \\
\hline \multirow{5}{*}{ Level 1} & $\mathrm{CF}_{1}$ & \multirow{2}{*}{$\mathbf{0}$} & \multirow{2}{*}{0.00} & 0.51 & 0.22 & 0.48 & 0.06 \\
\hline & $\mathrm{CF}_{2}$ & & & 0.49 & 0.22 & 0.52 & 0.06 \\
\hline & $\mathrm{CF}_{2-1}$ & \multirow{3}{*}{3} & \multirow{3}{*}{0.20} & 0.34 & 0.19 & 0.40 & 0.07 \\
\hline & $\mathrm{CF}_{2-2}$ & & & 0.26 & 0.09 & 0.32 & 0.06 \\
\hline & $\mathrm{CF}_{2-3}$ & & & 0.40 & 0.15 & 0.28 & 0.08 \\
\hline \multirow{6}{*}{ Level 2} & $\mathrm{CS}_{1}$ & \multirow{2}{*}{$\mathbf{0}$} & \multirow{2}{*}{0.00} & 0.46 & 0.26 & 0.48 & 0.09 \\
\hline & $\mathbf{C S}_{2}$ & & & 0.54 & 0.26 & 0.52 & 0.09 \\
\hline & $\mathrm{CS}_{2-1}$ & \multirow{4}{*}{5} & \multirow{4}{*}{0.22} & 0.24 & 0.13 & 0.20 & 0.04 \\
\hline & $\mathrm{CS}_{2-2}$ & & & 0.26 & 0.13 & 0.30 & 0.08 \\
\hline & $\mathrm{CS}_{2-3}$ & & & 0.35 & 0.13 & 0.32 & 0.06 \\
\hline & $\mathrm{CS}_{2-4}$ & & & 0.15 & 0.16 & 0.18 & 0.10 \\
\hline \multirow{5}{*}{ Level 3} & $\mathrm{CT}_{1}$ & \multirow{2}{*}{$\mathbf{0}$} & \multirow{2}{*}{0.00} & 0.44 & 0.23 & 0.47 & 0.06 \\
\hline & $\mathrm{CT}_{2}$ & & & 0.56 & 0.23 & 0.53 & 0.06 \\
\hline & $\mathrm{CT}_{2-1}$ & \multirow{3}{*}{6} & \multirow{3}{*}{0.22} & 0.32 & 0.17 & 0.38 & 0.08 \\
\hline & $\mathrm{CT}_{2-2}$ & & & 0.32 & 0.15 & 0.30 & 0.07 \\
\hline & $\mathrm{CT}_{2-3}$ & & & 0.36 & 0.21 & 0.32 & 0.06 \\
\hline
\end{tabular}

Note that criteria assessments are coherent, since the comparison of two criteria cannot lead to inconsistencies. In exchange, for the subcriteria assessments there are serious inconsistencies, so results from the AHP survey were discarded. This idea is confirmed when comparing standard deviations of both surveys: lower values are attained in the typical survey. Indeed, although AHP is a technique designed to reduce inconsistencies, the lack of familiarity of the surveyed experts with such tools leads to incoherencies. Therefore, the weights obtained with the typical survey are the ones considered as the starting weights in the design methodology (Table 2).

\section{Evaluation of alternatives and aggregation of results}

The evaluation of alternatives is a complex process where very different solutions must be compared using qualitative and quantitative criteria. However, in the problem dealt with in this paper, this process must be defined as simply as possible, and be transparent and easily represented in order to ease its diffusion among rural electrification promoters in developing regions. Compromise programming (Yu 1973; Zeleny 1973; Zeleny 1974) meets these requirements. First, some indicators are defined to objectively evaluate each 
alternative regarding each criterion (Section 5.1). Then, the technique used for the evaluation and ranking process is explained (Section 5.2).

Table 4 - Attributes and indicators for each criteria and subcriteria

\begin{tabular}{|c|c|c|c|c|c|}
\hline Criteria & Subcriteria & & Attributes & & Indicators \\
\hline $\mathbf{C F}_{1}$ & - & & - & $\mathbf{I F}_{1}$ & - Cost of the solution \\
\hline \multirow{3}{*}{$\mathrm{CF}_{2}$} & $\mathrm{CF}_{2-1}$ & $\mathbf{A F}_{\mathbf{2}}$ & Required energy by each point & $\mathbf{I F}_{2}$ & $+\mid \begin{array}{l}\text { Point with the lowest additional } \\
\text { percentage of energy supplied in } \\
\text { terms of the min. energy required }\end{array}$ \\
\hline & $\mathrm{CF}_{2-2}$ & $\mathbf{A F}_{3}$ & Required power by each point & $\mathrm{IF}_{3}$ & $+\begin{array}{l}\text { Point with the lowest additional } \\
\text { percentage of power supplied in } \\
\text { terms of the min. power required }\end{array}$ \\
\hline & $\mathrm{CF}_{2-3}$ & $\mathbf{A F}_{4}$ & Required autonomy & $\mathrm{IF}_{4}$ & $+\begin{array}{l}\text { Point with the lowest additional } \\
\text { percentage of autonomy available in } \\
\text { terms of the min. autonomy required }\end{array}$ \\
\hline $\mathrm{CS}_{1}$ & - & & - & $\mathbf{I S}_{\mathbf{1}}$ & - Cost of the solution \\
\hline \multirow{4}{*}{$\mathbf{C S}_{2}$} & $\mathbf{C S}_{2-1}$ & $\mathbf{A S}_{2}$ & Max. no. of microgrids & $\mathbf{I S}_{\mathbf{2}}$ & - No. of microgrids \\
\hline & $\mathbf{C S}_{2-2}$ & $\mathbf{A S}_{3}$ & Min. no. of users per microgrid & IS 3 & + No. of users of smallest microgrid \\
\hline & $\mathbf{C S}_{2-3}$ & $\mathbf{A S}_{4}$ & Max. no. of individual users & $\mathbf{I S}_{4}$ & - No. of individual users \\
\hline & $\mathrm{CS}_{2-4}$ & $\mathbf{A S}_{5}$ & Meters in all points or microgrids & $\mathbf{I S}_{5}$ & + No. of meters installed \\
\hline $\mathbf{C T}_{1}$ & - & & - & $\mathbf{I T}_{1}$ & - Cost of the solution \\
\hline \multirow{3}{*}{$\mathbf{C T}_{2}$} & $\mathrm{CT}_{2-1}$ & $\mathbf{A T}_{\mathbf{2}}$ & $\begin{array}{l}\text { Min. energy percentage generated } \\
\text { by PV panels at generation points }\end{array}$ & $\mathbf{I T}_{2}$ & $+\begin{array}{l}\text { Generation point with the lowest } \\
\text { percentage of energy from PV } \\
\text { panels in terms of total energy }\end{array}$ \\
\hline & $\mathrm{CT}_{2-2}$ & $\mathbf{A T}_{\mathbf{3}}$ & $\begin{array}{l}\text { Min. no. of generation equipment } \\
\text { at generation points }\end{array}$ & $\mathbf{I T}_{3}$ & $+\begin{array}{l}\text { Generation point with the lowest no. } \\
\text { of generation equipment installed }\end{array}$ \\
\hline & $\mathrm{CT}_{2-3}$ & $\mathbf{A T}_{\mathbf{4}}$ & $\begin{array}{l}\text { Min. additional energy } \\
\text { percentage at individual users in } \\
\text { terms of microgrid users }\end{array}$ & $\mathbf{I T}_{4}$ & $+\begin{array}{l}\text { Individual point with the lowest } \\
\text { additional percentage of energy } \\
\text { supplied in terms of the energy } \\
\text { requested by microgrid points }\end{array}$ \\
\hline
\end{tabular}

\subsection{Indicators for the evaluation of alternatives}

Table 4 lists the criteria and subcriteria for each decision level. Complementarily, an attribute is related to each subcriterion to specify the characteristic of the solutions to be studied. Additionally, the indicators allow assessing the compliance of each electrification alternative with each attribute. For example, within the criterion "demand" there is the subcriterion "energy", related to the attribute "required energy by each point"; the indicator used to measure the compliance with the attribute is the "point with the lowest percentage of energy supplied in terms of the minimum energy required".

Therefore, at Level 1 the decision-maker proposes several values of energy demand for each point (from now on called "admissible values of the attributes") and a different electrification alternative is generated in each case. The corresponding indicator is used to select the most suitable one; i.e. for each solution the "point with the lowest additional percentage of energy supplied in terms of the minimum energy required" is calculated. In this way a qualitative assessment can be carried out in order to ease decision-making, even for social criteria such as the management of the system or the adequacy of equipment. Finally, a $+/-$ column has been added, to specify if the indicators related to attributes must be maximized (+) or minimized (-). 
In Level 1 the cost and demand criteria are dealt with:

- $\operatorname{Cost}\left(C F_{1}\right)$. The minimum cost solution $\left(I F_{1}\right)$ is calculated for each set of admissible values of the attributes of the criterion demand. The lower this value, the better the alternative is ranked.

- Demand $\left(\mathrm{CF}_{2}\right)$.

- Energy $\left(\mathrm{CF}_{2-1}\right)$. Different admissible values of energy consumption are studied $\left(A F_{2}\right)$. The decision-maker must define a minimum energy value as well as percentage increases. The indicator $\left(I F_{2}\right)$ assesses the point with the lowest additional percentage of energy supplied by generators in terms of the minimum energy required. The higher this value, the better the alternative is ranked.

Note that electrification alternatives in which less favoured users are the least disadvantaged have the best ranking of all the alternatives. The same reasoning is valid for $I F_{3}, I F_{4}, I S_{3}, I T_{2}, I T_{3}$ and $I T_{4}$.

- Power $\left(C_{2-2}\right)$. Different admissible values of power consumption are studied $\left(A F_{3}\right)$. The decision-maker must define a minimum power value as well as percentage increases. The indicator $\left(I F_{3}\right)$ assesses the point with the lowest additional percentage of power supplied by inverters in terms of the minimum power required. The higher this value, the better the alternative is ranked.

- Autonomy $\left(C F_{2-3}\right)$. Different admissible values of autonomy are studied $\left(A F_{4}\right)$. The decision-maker must define a minimum autonomy value as well as percentage increases. The indicator $\left(I F_{4}\right)$ assesses the point with the lowest additional percentage of autonomy available in batteries in terms of the minimum autonomy required. The higher this value, the better the alternative is ranked.

Level 2 deals with the cost and management criteria of the system:

- Cost $\left(C S_{1}\right)$. The minimum cost solution $\left(I S_{1}\right)$ is calculated for each set of admissible values of the attributes of the criterion management of the system. The lower this value, the better the alternative is ranked.

- Management of the system $\left(\mathrm{CS}_{2}\right)$.

- Amount of microgrids $\left(C S_{2-1}\right)$. The decision-maker proposes a study of different admissible values of the maximum number of microgrids $\left(A S_{2}\right)$. The indicator $\left(I S_{2}\right)$ assesses the number of microgrids of the obtained solution. The lower this value, the better the alternative is ranked.

- Size of microgrids $\left(C S_{2-2}\right)$. The decision-maker proposes a study of different admissible values of the minimum number of users per microgrid $\left(A S_{3}\right)$. The indicator $\left(I S_{3}\right)$ assesses the number of users of the smallest microgrid. The higher this value, the better the alternative is ranked.

- Reach of microgrids $\left(C S_{2-3}\right)$. The decision-maker proposes a study of different admissible values of the maximum number of individual users $\left(A S_{4}\right)$. The indicator $\left(I S_{4}\right)$ assesses the number of individual users of the obtained solution. The lower this value, the better the alternative is ranked.

- Meters installation $\left(C_{2-4}\right)$. Two admissible values are studied for this attribute $\left(A S_{5}\right)$ : installing a meter at each point or only in microgrid points. The indicator $\left(I S_{5}\right)$ assesses the number of meters installed. The higher this value, the better the alternative is ranked. 
In Level 3 the cost and adequacy criteria of equipment are analysed:

- $\operatorname{Cost}\left(C T_{1}\right)$. The minimum cost solution $\left(I T_{1}\right)$ is calculated for each set of admissible values of the attributes of the criterion adequacy of equipment. The lower this value, the better the alternative is ranked.

- Adequacy of equipment (CT2).

- $P V$ generation percentage $\left(C T_{2-1}\right)$. The decision-maker proposes a study of the different admissible values of the minimum percentage of energy generated with $\mathrm{PV}$ panels at generation points $\left(A T_{2}\right)$. The indicator $\left(I T_{2}\right)$ assesses the generation point with the lowest percentage of energy supplied by PV panels in terms of the energy supplied by all the generators installed. The higher this value, the better the alternative is ranked.

- No. of generation equipment $\left(C T_{2-2}\right)$. The decision-maker proposes a study of the different admissible values of the maximum number of generators at generation points $\left(A T_{3}\right)$. The indicator $\left(I T_{3}\right)$ assesses the generation point with the lowest number of generators installed. The higher this value, the better the alternative is ranked.

- Energy of individual users $\left(C T_{2-3}\right)$. The decision-maker proposes a study of the additional energy percentage at individual users $\left(A T_{4}\right)$. The indicator $\left(I T_{4}\right)$ assesses the individual point with the lowest additional percentage of energy supplied in terms of the energy requested by microgrid points. The higher this value, the better the alternative is ranked.

\subsection{An adaptation of the compromise programming}

The goal of a multicriteria problem is to find the best solution from the point of view of all criteria. In this context, compromise programming starts from the principle that, if a decision-maker acts rationally, the best solution will be the one whose distance from an ideal solution is as low as possible (Yu 1973; Zeleny 1973). Thus, the set of efficient (or compromised) solutions can be found (Zeleny 1974). The ideal solution is defined as a non-feasible solution, i.e. one which does not comply with all the problem constraints; however, it does achieve optimum values in all criteria. Accordingly, the optimal solution is the alternative that, satisfying all the problem constraints, is closest to the ideal solution, as established by the Zeleny axiom (Zeleny 1973). Closeness is understood as the mathematical concept of distance. Therefore, compromise programming can be formulated by the following mathematical model (Zeleny 1973):

$$
[M I N] L_{p}=\left[\sum_{i=1}^{n} W_{i}^{p}\left(\frac{F_{i}^{*}-f_{i}(x)}{F_{i}^{*}-f_{i}^{*}}\right)^{p}\right]^{1 / p}
$$

Subject to:

$$
x \in X
$$

where $p$ is the metric used; $L_{p}$ is the distance between the alternative and the ideal solution; $W_{i}$ is the weight of criterion $i$ (discussed in Section 4.3); $f_{i}(x)$ is the evaluation of the alternative for the criterion $i$, i.e. the indicator (discussed in Section 5.1); $F_{i}{ }^{*}$ is the ideal (best) value for the criterion $i ; f_{i}{ }^{*}$ is the anti-ideal (worst) value for the criterion $i ; n$ is the number of criteria; $x$ is the set of decision variables of the problem; and $X$ is the set of feasible solutions delimited by problem constraints. Additionally, note that in the objective function the distance between ideal $\left(F_{i}{ }^{*}\right)$ and alternative $\left(f_{i}(x)\right)$ values is 
normalized by dividing it by the difference between ideal $\left(F_{i}{ }^{*}\right)$ and anti-ideal $\left(f_{i}^{*}\right)$ values. This is due to the fact that the indicators used to evaluate alternatives can be measured in different units. Their comparison is made easier by normalizing them.

Usually, compromise programming proposes solving the previous mathematical model in order to find the closest alternative to the ideal solution. Fig. 4 shows how this tool works in the case of the first decision level, where the criteria cost and demand are dealt with. The black curve represents efficient alternatives, i.e. which minimize the cost of a specific demand value. The upper space represents feasible but non-efficient solutions, while the lower space represents non-feasible solutions. The black curve is delimited by the two extreme solutions (red crosses), one with the highest demand and the other with the lowest cost. In turn, both solutions define the ideal solution (orange triangle), which is a utopian solution with the maximum demand and the minimum cost. In typical compromise programming, the previous mathematical model would be solved. Depending on the metric $p$ used (which is discussed later in this section) the solution will be one or another from the black curve. However, it has been demonstrated that for problems with two criteria the best solution can be found within the compromised set (green dashed-line), which is delimited by the solutions obtained for metrics $p=1$ and $p=\infty$ (green squares), according to the Yu theorem (Yu 1973).

However, our work is slightly different since a set of efficient solutions has already been generated (blue dots and red crosses) and the aim is to rank them. Therefore, the distance $L_{p}$ can be calculated for each alternative and then this value can be used to classify the alternatives and to select the best one (lowest $L_{p}$ ).

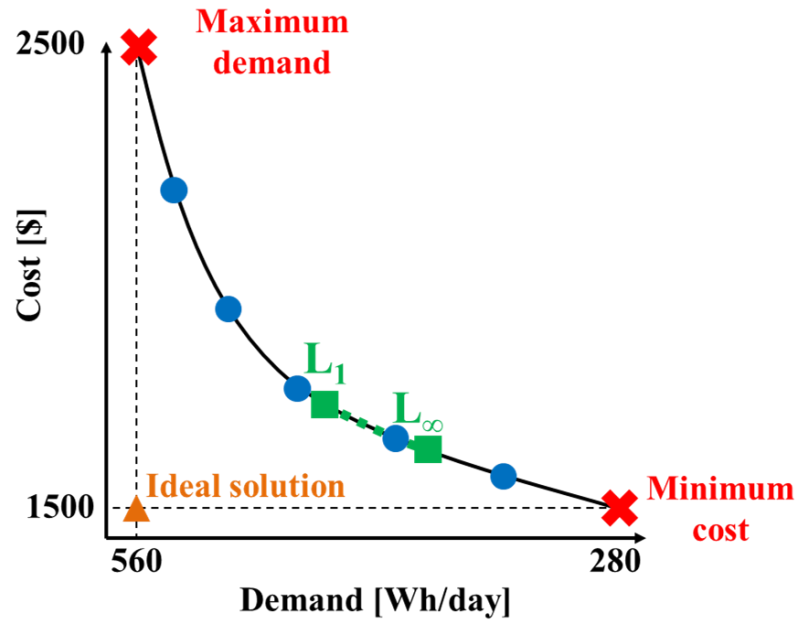

Fig. 4 - Use of compromise programming to solve the first decision level

To conclude the explanation, next the way to choose the metric $p$ is explained. Deciding the most adequate metric is a complex and confusing problem. Most of the reviewed works discuss the results according to different metrics in order to draw some recommendations about the studied problem (Merino et al. 2003; André and Romero 2006). However, in this work a single ranking and selection must be proposed at each level, without the intervention of the decision-maker. Therefore, a metric must be chosen. The metric represents the importance assigned to the deviation with regard to the ideal of each criterion; or in other words, the frustration regarding each criterion. Thus, the higher the metric value the more significance assigned to the maximum deviation (Hashimoto and $\mathrm{Wu} 2004$ ). Some of the most common metrics are 1, 2 and $\infty$. For $p=1$ (Manhattan 
distance) the relevance of the frustration regarding each criterion is proportional to the weight of the criterion. For $p=2$ (Euclidean distance) the minimum geometric distance is studied. Finally, for $p=\infty$ (Tchebycheff distance) only the criterion with maximum deviation is considered.

As a general rule, the value $p$ to be selected depends on the type of problem and the decision-maker. The more the unrest between decision-makers, the lower the metric recommended. Lower $p$ values allow undervalues in some criteria to be compensated by overvalues in other criteria, while higher $p$ values avoid this situation (Poff et al. 2010). However, no rationale exists for choosing one metric or another (Hashimoto and $\mathrm{Wu}$ 2004). In this context, Díaz-Balteiro and Romero (2004) propose a linear combination of $L_{1}$ y $L_{\infty}$ to ensure flexibility in terms of the characteristics of each problem and decisionmaker. This option represents an equilibrium between "maximum aggregated value" $\left(L_{1}\right)$ and "most balanced value" $\left(L_{\infty}\right)$, depending on a calibration parameter $\alpha\left(L_{F}=\alpha \cdot L_{1}+[1\right.$ $\left.\alpha] \cdot L_{\infty}\right)$. In this work this linear combination is used, with $\alpha=0.5$ as occurs in the literature (San Cristóbal 2011).

\section{Illustration of the multicriteria procedure}

To illustrate the proposed multicriteria procedure for selecting the most suitable electrification alternative from a set of previously generated ones, the case study of Domenech et al. (2015a) is utilized. In that work, emphasis is put on the methodology framework, while this paper is focused on the way the decisions are taken following the multicriteria procedure. For this purpose, a highly experienced electrification promoter, an active member of EWB, the NGO in charge of the electrification project implementation, has been involved in taking decisions during the design process.

The case study is based on the real community of Alto Peru in the Andean highlands. To illustrate the process, the electrification project of the highest part of the community will be designed, which includes 5 houses and a communal centre. First, the socioeconomic characteristics of the population were assessed. The energy demand was set to $600 \mathrm{Wh} /$ day for the communal centre and $300 \mathrm{Wh} /$ day for houses; the power demand was set to $500 \mathrm{~W}$ for the communal centre and $200 \mathrm{~W}$ for houses. Moreover, the wind and sun resources in the region were studied, determining the energy potential at each point of the community as well as an autonomy demand of 2 days, according to resource variability. Additionally, information on the cost and specifications of equipment available in the market was gathered.

\subsection{Level 1 - Strategic decisions - Cost vs Demand}

In Level 1 , the decision-maker proposes a minimum energy $\left(A F_{2}\right)$ and power $\left(A F_{3}\right)$ demand, according to the input data gathered from the community analysis; two further scenarios are added by increasing the demand by $25 \%$ and $50 \%$. In contrast, the same autonomy demand is considered for the three scenarios. These are the admissible values of the attributes (Fig. 5, Table A).

With this information, three electrification alternatives (A1, A2 and A3) are generated using the mathematical model mentioned in Section 3.3 (Domenech et al. 2015b). The outputs of the model are shown to the decision-maker, expressed through the indicators 
(Fig. 5, Table B). The cost is presented in US dollars, while the other values are presented as the additional percentage with regard to the minimum demand, as defined in Table 4 (Section 5.1). For instance, an admissible value of $25 \%$ for the energy attribute $\left(A F_{2}\right)$ is introduced into the model for alternative A2 $(750 \mathrm{Wh} /$ day for the communal centre and $375 \mathrm{Wh}$ /day for houses). This represents a $25 \%$ increase with regard to the minimum demand $(600 \mathrm{Wh} /$ day for the communal centre and $300 \mathrm{Wh}$ /day for houses). As a result, in the solution generated, the point in the worst situation has an additional energy percentage of $26 \%$ in terms of its minimum demand, as shown by indicator $I F_{2}$.

Table A

Admissible values of the attributes

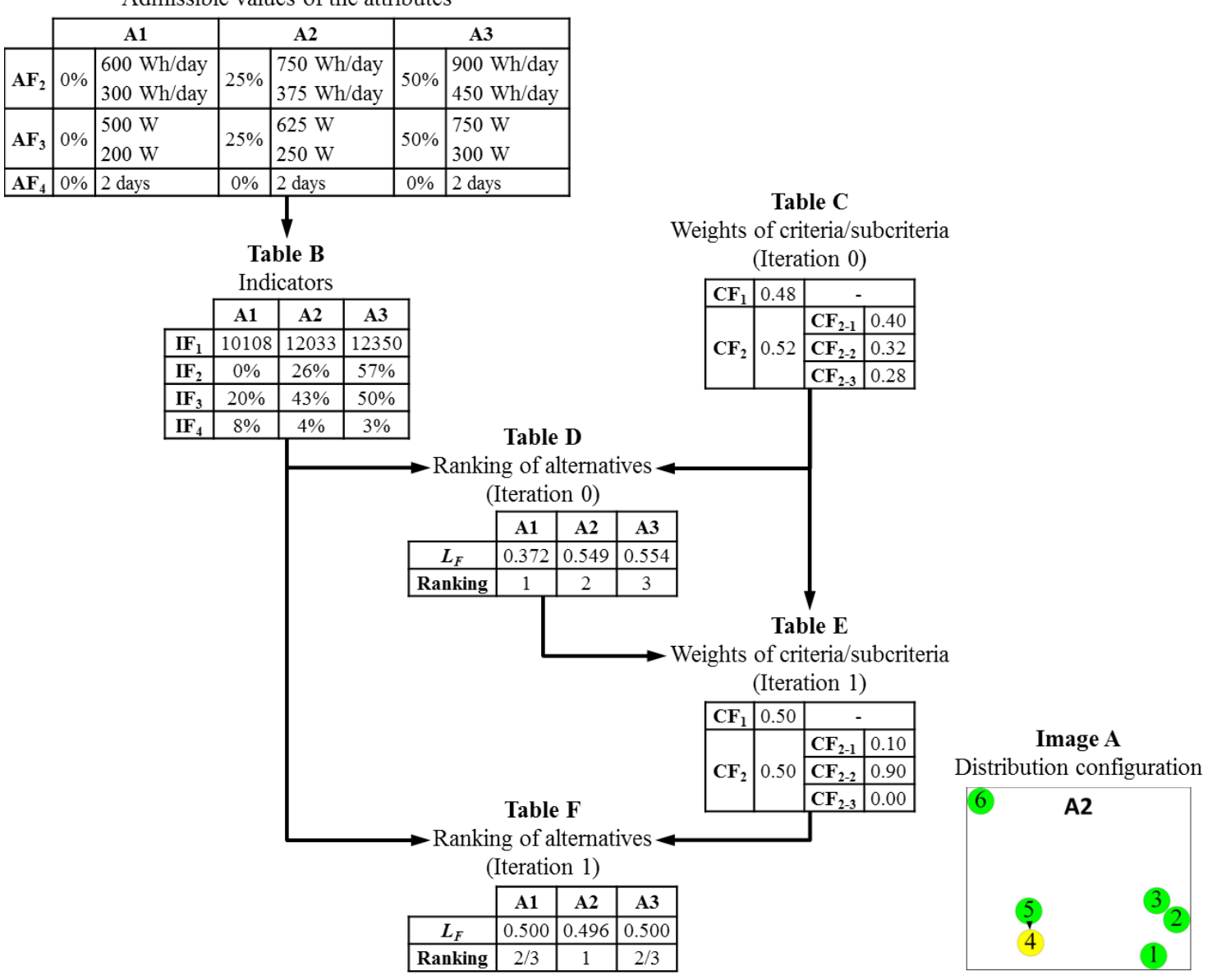

Fig. 5 - Decision-making scheme followed in Level 1

At this point an initial ranking of generated alternatives is automatically calculated. To do so, the indicators (Fig. 5, Table B) and the starting weights of criteria (Fig. 5, Table C) - determined in Section 3.1 - are used to calculate the value $L_{F}$ for each alternative (Fig. 5, Table D), following the formula explained in Section 5.2. As can be seen, the topranked alternative, i.e. the most compromised between criteria cost and demand, is A1 (lowest $L_{F}$ value), followed by A2 and then A3. However, the decision-maker considers that this initial ranking does not match her preferences, so modifies the weights of the criteria and subcriteria (Fig. 5, Table E). Consequently, a new $L_{F}$ value for each alternative, and a new ranking, is obtained (Fig. 5, Table F). In this case, the top-ranked alternative is A2, followed by $\mathrm{A} 1$ and $\mathrm{A} 3$. Note that the indicators are maintained, since the alternatives to be ranked are still the same. To finalise the first decision level, the decision-maker selects the most suitable alternative (A2) for the next level; see Fig. 5, Image A. 


\subsection{Level 2 - Tactical decisions - Cost vs Management of the system}

In Level 2, the decision-maker proposes two different scenarios for the maximum number of microgrids $\left(A S_{2}\right)$, the minimum number of users per microgrid $\left(A S_{3}\right)$ and meter installation $\left(A S_{5}\right)$. These are the admissible values of the attributes (Fig. 6, Table A). Note that an admissible value, which cannot be exceeded in any situation, is given for the maximum number of individual users $\left(A S_{4}\right)$ at all the alternatives, since this attribute is not studied.

Table A

Admissible values of the attributes (Iteration 0)

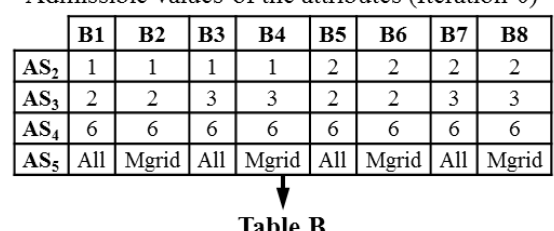

Indicators (Iteration 0)

Table C

Weights of criteria/subcriteria

\begin{tabular}{|c|c|c|c|c|c|c|c|c|}
\cline { 2 - 9 } \multicolumn{1}{c|}{} & B1 & B2 & B3 & B4 & B5 & B6 & B7 & B8 \\
\hline $\mathbf{I S}_{\mathbf{1}}$ & 12033 & 11833 & 15518 & 15468 & 12033 & 11833 & 15518 & 15468 \\
\hline $\mathbf{I S}_{\mathbf{2}}$ & 1 & 1 & 1 & 1 & 1 & 1 & 1 & 1 \\
\hline $\mathbf{I S}_{\mathbf{3}}$ & 2 & 2 & 5 & 5 & 2 & 2 & 5 & 5 \\
\hline $\mathbf{I S}_{\mathbf{4}}$ & 4 & 4 & 1 & 1 & 4 & 4 & 1 & 1 \\
\hline $\mathbf{I S}_{\mathbf{5}}$ & 6 & 2 & 6 & 5 & 6 & 2 & 6 & 5 \\
\hline
\end{tabular}

Table D

Ranking of alternatives (Iteration 0)

\begin{tabular}{|c|c|c|c|c|c|c|c|c|}
\hline \multicolumn{1}{|c|}{ Ranking of alternatives (Iteration 0) } \\
\cline { 2 - 10 } & B1 & B2 & B3 & B4 & B5 & B6 & B7 & B8 \\
\hline $\boldsymbol{L}_{F}(\boldsymbol{x})$ & 0.410 & 0.517 & 0.483 & 0.491 & 0.410 & 0.517 & 0.483 & 0.491 \\
\hline Ranking & $1 / 2$ & $7 / 8$ & $3 / 4$ & $5 / 6$ & $1 / 2$ & $7 / 8$ & $3 / 4$ & $5 / 6$ \\
\hline
\end{tabular}

Table $\mathbf{E}$

Admissible values of the attributes (Iteration 1)

\begin{tabular}{|l|l|l|l|l|l|l|l|l|l|}
\hline B1 & B3 & B9 & B10 & B11 & B12 & B13 & B14 & B15 & B16 \\
\hline
\end{tabular}

\begin{tabular}{|l|c|c|c|c|c|c|c|c|c|c|c|}
\hline $\mathbf{A S}_{\mathbf{2}}$ & 1 & 1 & 1 & 1 & 1 & 1 & 2 & 2 & 2 & 2 \\
\hline $\mathbf{A S}_{\mathbf{3}}$ & 2 & 3 & 2 & 2 & 3 & 3 & 2 & 2 & 3 & 3 \\
\hline $\mathbf{A S}_{\mathbf{4}}$ & 6 & 6 & 6 & 0 & 6 & 0 & 6 & 0 & 6 & 0 \\
\hline $\mathbf{A S}_{\mathbf{5}}$ & All & All & All & All & All & All & All & All & All & All \\
\hline \multicolumn{10}{|}{ Table F }
\end{tabular}

Indicators (Iteration 1)

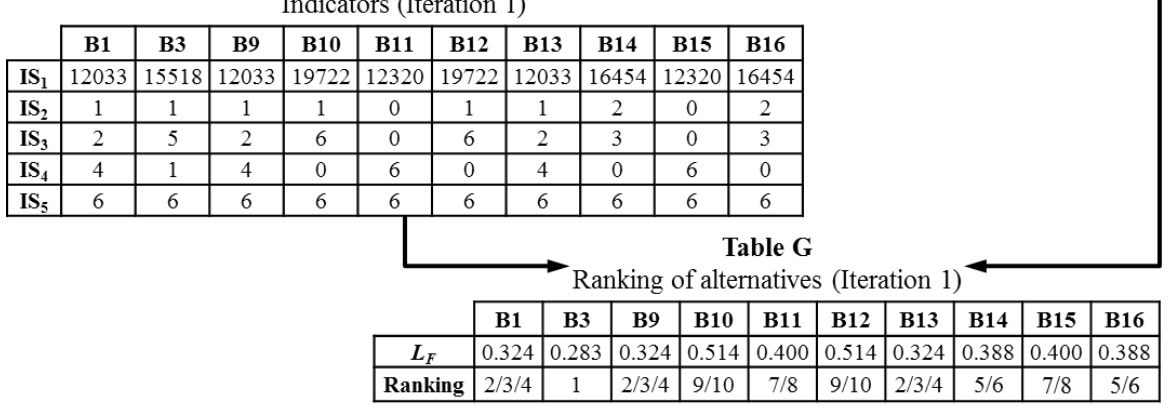

Fig. 6 - Decision-making scheme followed in Level 2
Image A

Distribution configuration

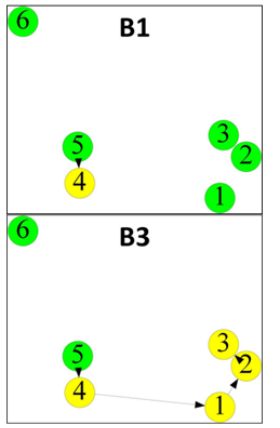

Using this information, eight electrification alternatives (B1 to B8) are generated. The indicators (Fig. 6, Table B) are presented to the decision-maker. Using the indicators and the starting weights of the criteria (Fig. 6, Table C), the value $L_{F}$ is calculated for each alternative, thus obtaining an initial ranking (Fig. 6, Table D). In this case, the decisionmaker maintains the weights and selects the two top-ranked alternatives (B1 and B3), but decides to generate a new set of alternatives. To do so, she proposes the same two scenarios for $A S_{2}$ and $A S_{3}$, two new scenarios for $A S_{4}$ and a single scenario for $A S_{5}$. The new admissible values are shown in Fig. 6, Table E. 
With this information, eight new electrification alternatives (B9 to B16) are generated. The indicators (Fig. 6, Table F) are presented to the decision-maker. Using the indicators and the starting weights of the criteria (Fig. 6, Table C), the value $L_{F}$ is calculated for each alternative, thus obtaining an initial ranking (Fig. 6, Table G). Now, the decisionmaker selects the two top-ranked alternatives, which again are B1 and B3, for the next level; shown in Fig. 6, Image A.

\subsection{Level 3 - Operational decisions - Cost vs Adequacy of equipment}

In Level 3, the two alternatives selected in the previous level are studied in parallel.

For alternative B1, the decision-maker proposes two different scenarios for the minimum quantity of generation equipment $\left(A T_{3}\right)$, the additional energy percentage at individual users $\left(A T_{4}\right)$, not studying the minimum energy percentage generated by PV panels $\left(A T_{2}\right)$. These are the admissible values of the attributes (Fig. 7, Table A). With this information, two electrification alternatives $(\mathrm{C} 1$ and $\mathrm{C} 2$ ) are generated, whose indicators (Fig. 7, Table B) are presented to the decision-maker. Using the indicators and the starting weights of the criteria (Fig. 7, Table C), the value $L_{F}$ is calculated for each alternative, thus obtaining an initial ranking (Fig. 7, Table D). The decision-maker selects the top-ranked alternative C2; shown in Fig. 7, Image A.

Table A

Admissible values of the attributes

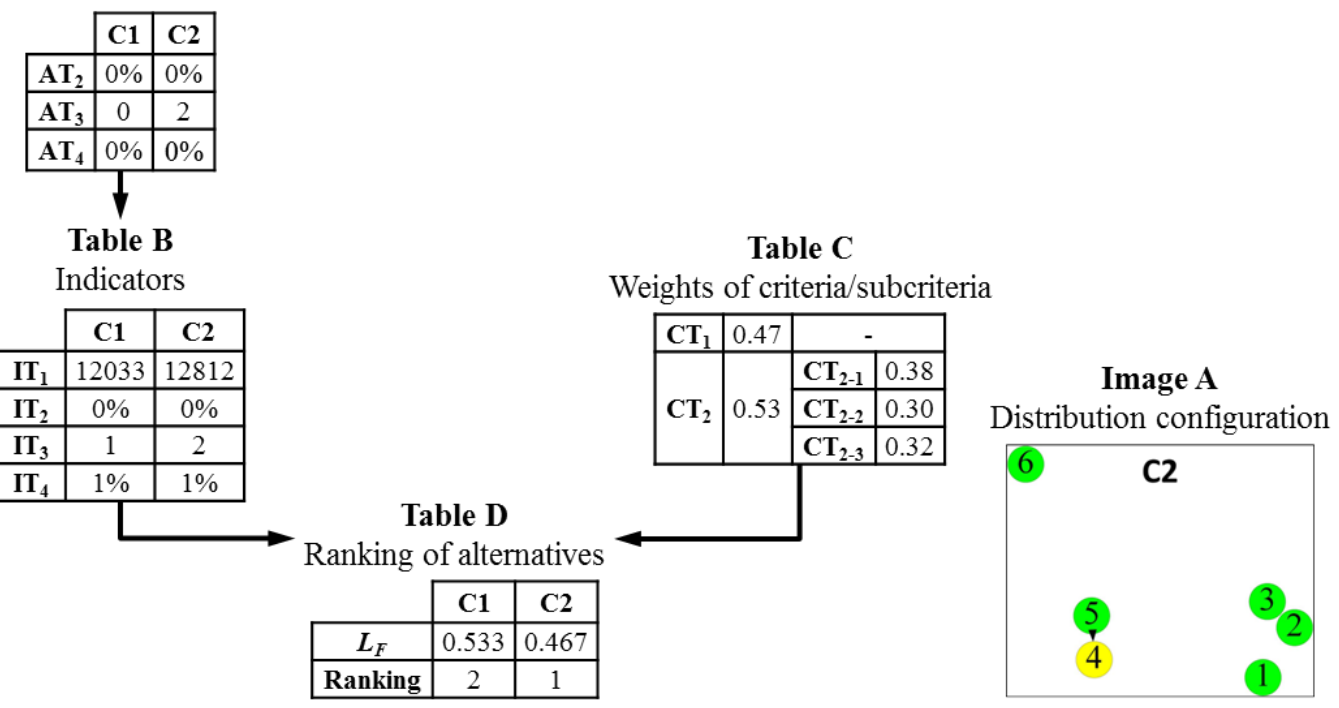

Fig. 7 - Decision-making scheme followed in Level 3, Alternative B1

For alternative B3, the decision-maker proposes two different scenarios for $A T_{3}$ and $A T_{4}$, not studying $A T_{2}$, as shown in the admissible values of the attributes (Fig. 8, Table A). With this information, four electrification alternatives (C3 to $\mathrm{C} 4)$ are generated, whose indicators (Fig. 8, Table B) are presented to the decision-maker. Using the indicators and the starting weights of the criteria (Fig. 8, Table C), the value $L_{F}$ is calculated for each alternative, thus obtaining an initial ranking (Fig. 8, Table D). The decision-maker selects the two top-ranked alternatives $\mathrm{C} 4$ and $\mathrm{C} 5$; as shown in Fig. 8, Image A. 
Table A

Admissible values of the attributes

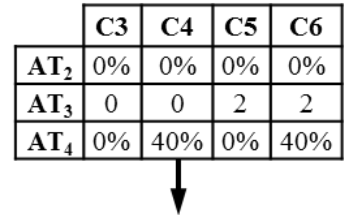

Table B

Indicators

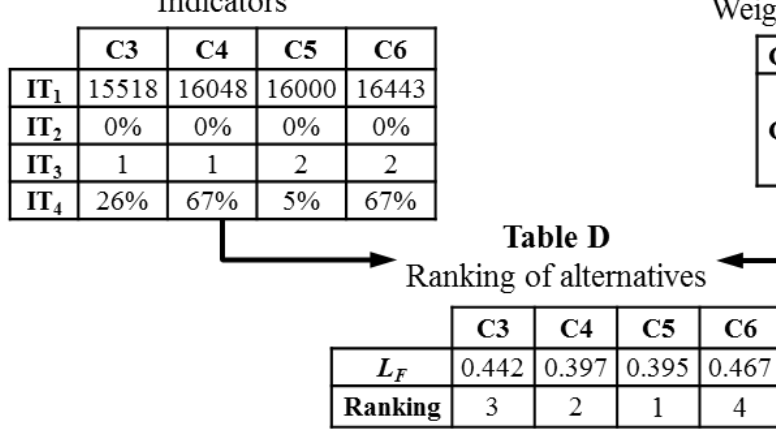

Table C

Weights of criteria/subcriteria

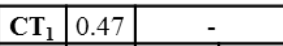

\begin{tabular}{|l|l|l|}
\hline & $\mathbf{C T}_{2-1}$ & 0.38 \\
\cline { 2 - 4 } \\
\cline { 2 - 4 }
\end{tabular}

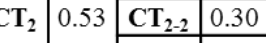
\begin{tabular}{|l|l|l|}
\hline $\mathbf{C T}_{2-3}$ & 0.32 \\
\hline
\end{tabular}

Distribution configuration

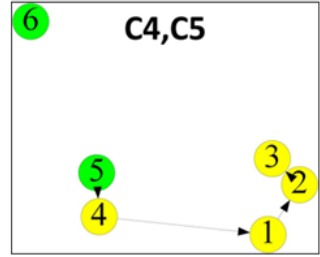

Fig. 8 - Decision-making scheme followed in Level 3, Alternative B3

\subsection{Final decision}

At this point, three alternatives are available for selection. To choose the best one, the decision-maker considers the specific characteristics of the studied community and its population. In particular, she selects the alternative $\mathrm{C} 4$ since it has more microgrid users than $\mathrm{C} 2$, so its benefits reach more beneficiaries and compensates for increases in cost; it also offers more energy to individual users than $\mathrm{C} 5$, at a similar cost.

\section{Conclusions}

In order assist rural electrification promoters in the design of wind-PV stand-alone electrification projects combining microgrids and individual systems while including economical, technical and social aspects, a multicriteria procedure is developed. The decision-making is structured in four parts, which are developed and presented in detail. First, some criteria are defined through rural electrification expert consultations. Although 28 criteria were initially proposed, a reduced and easy-to-handle set of criteria (each one including subcriteria) is defined. Second, the experts are interviewed to set the weights of criteria, using a pair-wise AHP comparison and a typical 1-10 survey, which reveals to be more representative of expert preferences given their higher familiarity with such a technique. Third, an indicator related to each criterion and subcriterion is defined to evaluate the accomplishment of each solution, avoiding subjectivities. Fourth, considering the weights and indicators, the solutions are ranked adapting the compromise programming into a discrete multicriteria technique, balancing the maximum aggregated $\left(L_{1}\right)$ and the most balanced solutions $\left(L_{\infty}\right)$. The whole multicriteria procedure is illustrated through its use to design the electrification project of a real community in the Andean highlands. Thus, the way as decisions are taken is shown and the procedure proves to be useful to assist rural electrification promoters in projects design.

The proposed multicriteria procedure shows significant benefits. On the one hand, not the cheapest solution, but the most compromised between the minimum cost, the maximum energy uses covered, the easier management of the system and the better adequacy of 
equipment is found. In fact, the solution finally selected for the case study reaches an equilibrium between the cost, the demand supplied, and structure of the electricity configuration and the suitability of the equipment implemented. On the other hand, a very high detail of the solutions is designed, simultaneously defining the electricity generation and distribution systems in an interactive framework. Therefore, end-users become active stakeholders in the definition of the electrification system, instead of passive beneficiaries of a given solution. This is expected to promote their confidence on the electrification solution finally implemented. Finally, a very large amount of electrification options can be tested, which may be useful to justify the solution chosen both in front of end-users and funding institutions, without having to invest a high amount of time and resources for such a calculus. As future research, the authors are working on finding new contexts where the procedure can be tested in order to expand the scope of communities focused. In particular, new criteria could be included to reflect to characteristics of different regions, such as environmental issues.

\section{Acknowledgements}

The authors are very grateful to the NGOs Practical Action - Intermediate Technology Development Group (Peru), Engineering Without Borders (Spain) and Green Empowerment (USA) for all the support and assistance given during the development of this research. This research was funded by the Spanish Ministry of Science and Innovation (project ENE 2015-67253-R) and the Centre for Cooperation Development (CCD) of the Universitat Politècnica de Catalunya - Barcelona TECH (UPC).

\section{References}

Afgan, N. H., Carvalho, M. G., \& Hovanov, N. V. (2000). Energy system assessment with sustainability indicators. Energy Policy, 28, 603-612.

Alarcón-Rodriguez, A., Ault, G., \& Galloway, S. (2010). Multi-objective planning of distributed energy resources: A review of the state-of-the-art. Renewable and Sustainable Energy Reviews, 14, 1353-1366.

Alfaro, J. F., Miller, S., Johnson, J. X., \& Riolo, R. R. (2017). Improving rural electricity system planning: an agent-based model for stakeholder engagement and decision making. Energy Policy, 101, 317-331.

André, F. J., \& Romero, C. (2006). On the equivalence between compromise programming and the use of composite compromise metrics. Working Papers Series, WP Econ 06.33.

Atamtürk, A., \& Savelsbergh, M. W. P. (2005). Integer-programming software systems. Annals of Operations Research, 140, 67-124.

Baños, R., Manzano-Agugliaro, F., Montoya, F. G., Gil, C., Alcayde, A., \& Gómez, J. (2011). Optimization methods applied to renewable and sustainable energy: A review. Renewable and Sustainable Energy Reviews, 15, 1753-1766.

Bertsch, V., \& Fichtner, W. (2016). A participatory multi-criteria approach for power generation and transmission planning. Annals of Operations Research, 245, 177-207.

Bhattacharyya, S. C. (2012). Review of alternative methodologies for analysing off-grid electricity supply. Renewable and Sustainable Energy Reviews, 16, 677- 694.

Chatzimouratidis, A. I., \& Pilavachi, P. A. (2009). Technological, economic and sustainability evaluation of power plants using the Analytic Hierarchy Process. Energy Policy, 37, 778-787.

Chaurey, A., \& Kandpal, T. C. (2010). A techno-economic comparison of rural electrification based on solar home systems and PV microgrids. Energy Policy, 38, 3118-3129.

Colapinto, C., Jayaraman, R., \& Marsiglio, S. (2017). Multi-criteria decision analysis with goal programming in engineering, management and social sciences: a state-of-the art review. Annals of Operations Research, 251, 7-40.

Díaz-Balteiro, L., \& Romero, C. (2004). In search of a natural systems sustainability index. Ecological Economics, 49, 401-405.

Dinçer, F. (2011). The analysis on photovoltaic electricity generation status, potential and policies of the leading countries in solar energy. Renewable and Sustainable Energy Reviews, 15, 713-720. 
Domenech, B., Ferrer-Martí, L., Lillo, P., Pastor, R., \& Chiroque, J. (2014). A community electrification project: Combination of microgrids and household systems fed by wind, PV or micro-hydro energies according to micro-scale resource evaluation and social constraints. Energy for Sustainable Development, 23, 275-285.

Domenech, B., Ferrer-Martí, L., \& Pastor, R. (2015a). Hierarchical methodology to optimize the design of stand-alone electrification systems for rural communities considering technical and social criteria. Renewable and Sustainable Energy Reviews, 51, 182-196.

Domenech, B., Ferrer-Martí, L., \& Pastor, R. (2015b). Including management and security of supply constraints for designing stand-alone electrification systems in developing countries. Renewable Energy, 80, 359-369.

Escobar, R., Vilar, D., Velo, E., Ferrer-Martí, L., \& Domenech, B. (2012). Promoting and improving renewable energy projects through local capacity development. In: A. S. Sahin (Ed.), Modeling and optimization of renewable energy systems (pp. 147-170). Croatia: Intech.

Ferrer-Martí, L., Garwood, A., Chiroque, J., Ramírez, B., Marcelo, O., Garfí, M., \& Velo, E. (2012). Evaluating and comparing three community small-scale wind electrification projects. Renewable and Sustainable Energy Reviews, 16, 5379-5390.

Gamarra, C., \& Guerrero, J. M. (2015). Computational optimization techniques applied to microgrids planning: A review. Renewable and Sustainable Energy Reviews, 48, 413-424.

Garcia-Bernabeu, A., Benito, A., Bravo, M., \& Pla-Santamaria, D. (2016). Photovoltaic power plants: a multicriteria approach to investment decisions and a case study in western Spain. Annals of Operations Research, 245, 163-175.

García-Cascales, M. S., Lamata, M. T., \& Sánchez-Lozano, J. M. (2012). Evaluation of photovoltaic cells in a multi-criteria decision making process. Annals of Operations Research, 199, 373-391.

Garfí, A., Ferrer-Martí, L., Bonoli, A., \& Tondelli, S. (2011). Multicriteria analysis for improving strategic environmental assessment of water programs. A case study in semi-arid region of Brazil. Journal of Environmental Management, 92, 665-675.

Hashimoto, A., \& Wu, D. A. (2004). A DEA-compromise programming model for comprehensive ranking. Journal of Operational Research of Japan, 47, 73-81.

Henao, F., Cherni, J. A., Jaramillo, P., \& Dyner, I. (2012). A multicriteria approach to sustainable energy supply for the rural poor. European Journal of Operational Research, 218, 801-809.

Hiremath, R. B., Shikha, S., \& Ravindranath, N. H. (2007). Decentralized energy planning, modelling and application: a review. Renewable and Sustainable Energy Reviews, 11, 729-752.

IEA. (2017). World energy outlook. Paris: International Energy Agency.

Karger, C. R., \& Hennings, W. (2009). Sustainability evaluation of decentralized generation. Renewable and Sustainable Energy Reviews, 13, 583-593.

Kuznia, L., Zeng, B., Centeno, G., \& Miao, Z. (2013). Stochastic optimization for power system configuration with renewable energy in remote areas. Annals of Operations Research, 210, 411-432.

Lal, D. K., Dash, B. B., \& Akella, A. K. (2011). Optimization of PV/wind/micro-hydro/diesel hybrid power system in HOMER for the study area. International Journal on Electrical Engineering and Informatics, 3, 307-325.

Lambert, T. W., \& Hittle, D. C. (2000). Optimization of autonomous village electrification systems by simulated annealing. Solar Energy, 68, 121-132.

Leary, J., While, A., \& Howell, R. (2012). Locally manufactured wind power technology for sustainable rural electrification. Energy Policy, 43, 173-183.

Lillo, P., Ferrer-Martí, L., Fernández-Baldor, A., \& Ramírez, B. (2015). A new integral management model and evaluation method to enhance sustainability of renewable energy projects for energy and sanitation services. Energy for Sustainable Development, 29, 1-12.

Loken, E. (2007). Use of multicriteria decision analysis methods for energy planning problems. Renewable and Sustainable Energy Reviews, 11, 1584-1595.

Malekpoor, H., Chalvatzis, K., Mishra, N., \& Ramudhin, A. (2018). A hybrid approach of VIKOR and biobjective integer linear programming for electrification planning in disaster relief camp. Annals of Operations Research. DOI: 10.1007/s10479-018-2877-0.

Mardani, A., Jusoh, A., Zavadskas, E. K., Cavallaro, F., \& Khalifah, Z. (2015). Sustainable and renewable energy: An overview of the application of multiple criteria decision making techniques and approaches. Sustainability, 7, 13947-13984.

Mavrotas, G., Diakoulaki, D., \& Capros, P. (2003). Combined MCDA-IP approach for project selection in the electricity market. Annals of Operations Research, 120, 159-170.

Merino, G. G., Jones, D. D., Clements, D. L., \& Miller, D. (2003). Fuzzy compromise programming with precedence order in the criteria. Applied Mathematics and Computation, 13, 185-205. 
Nijkamp, P., Reitveld, P., \& Voogd, H. (1990). Multicriteria Evaluation in Physical Planning. North Holland, Amsterdam: Elsevier Science.

Notton, G., Diaf, S., \& Stoyanov, L. (2011). Hybrid photovoltaic/wind energy systems for remote locations. Energy Procedia, 6, 666-677.

Ostergaard, P. A. (2009). Reviewing optimization criteria for energy systems analyses of renewable energy integration. Energy, 34, 1236-1245.

Poff, B., Tecle, A., Neary, D. G., \& Geils, B. (2010). Compromise programming in forest management. Journal of the Arizona-Nevada Academy of Science, 42, 44-60.

Phrakonkham, S., Le Chenadec, J. Y., Diallo, D., Remy, G., \& Marchand, C. (2010). Reviews on microgrid configuration and dedicated hybrid system optimization software tools: Application to Laos. Engineering Journal, doi: 10.4186/ej.2010.14.3.15.

Pohekar, S. D., \& Ramachandran, M. (2004). Application of multi-criteria decision making to sustainable energy planning - A review. Renewable and Sustainable Energy Reviews, 8, 365-381.

Polatidis, H., Haralambopoulos, D. A., Munda, G., \& Vreeker, R. (2006). Selecting an appropriate multicriteria analysis technique for renewable energy planning. Energy Sources, 1, 181-193.

Rojas-Zerpa JC. (2012). Planning the electricity supply in rural áreas of developing countries: a reference framework for decision-making. PhD Thesis, University of Zaragoza.

Rojas-Zerpa, J. C., \& Yusta, J. M. (2014). Methodologies, technologies and applications for electric supply planning in rural remote areas. Energy for Sustainable Development, 20, 66-76.

Rojas-Zerpa, J. C., \& Yusta, J. M. (2015). Application of multicriteria decision methods for electric supply planning in rural and remote areas. Renewable and Sustainable Energy Reviews, 52, 557-571.

Saaty, T. L. (2003). Decision-making with the AHP: Why is the principal eigenvector necessary? European Journal of Operational Research, 145, 85-91.

San Cristóbal, J. R. (2011). Multi-criteria decision-making in the selection of a renewable energy project in Spain: The VIKOR method. Renewable Energy, 36, 498-502.

Sanchez-López, R., Bana e Costa, C. A., \& De Baets, B. (2012). The MACBETH approach for multicriteria evaluation of development projects on cross-cutting issues. Annals of Operations Research, 199, 393-408.

Schäfer, M., Kebir, N., \& Neumann, K. (2011). Research needs for meeting the challenge of decentralized energy supply in developing countries. Energy for Sustainable Development, 15, 324-329.

Schäfer, M. (2015). Micro perspectives for decentralized energy supply. Proceedings of the International Conference, Berlin. ISBN: 978-3-7983-2744-3.

Scott, G. (2001). Strategic planning for high-tech product development. Technology Analysis and Strategic Management, 13, 343-364.

Ubilla, K., Jiménez-Estévez, G. A., Hernádez, R., Reyes-Chamorro, L., Hernández-Irigoyen, C., Severino, B., et al. (2014). Smart microgrids as a solution for rural electrification: Ensuring long-term sustainability through cadastre and business models. IEEE Transactions on Sustainable Energy, 5, 13101318.

UN. (2015). Transforming our world: the 2030 agenda for Sustainable Development. Paris: United Nations.

Ustun, T. S., Ozansoy, C., \& Zayegh, A. (2011). Recent developments in microgrids and example cases around the world - A review. Renewable and Sustainable Energy Reviews, 15, 4030-4041.

Wang, J. J., Jing, Y. Y., Zhang, C. F., \& Zhao, J. H. (2009). Review on multi-criteria decision analysis aid in sustainable energy decision-making. Renewable and Sustainable Energy Reviews, 13, 2263-2278.

Yu, P. L. (1973). A class of solution for group decision problem. Management Science, 19, 936-946.

Zeleny, M. (1973). Compromise programming. Multiple criteria decision making. University of South Carolina Press, Columbia, 263-301.

Zeleny, M. (1974). A concept of compromise solutions and the method of the displaced ideals. Computers and Operational Research, 1, 479-496.

Zhou, P., Ang, B. W., \& Poh, K. L. (2006). Decision analysis in energy and environmental modelling: An update. Energy, 31, 2604-2622.

Zhou, W., Lou, C., Li, Z., Lu, L., \& Yang, H. (2010). Current status of research on optimum sizing of standalone hybrid solar-wind power generation systems. Applied Energy, 87, 380-389. 